\title{
COMÉRCIO INTERNACIONAL E CONSUMISMO: INTERFACE PARA UM DIREITO GLOBAL DO CONSUMIDOR
}

\section{INTERNATIONAL TRADE AND CONSUMERISM: INTERFACE FOR A GLOBAL CONSUMER LAW}

\author{
${ }^{1}$ Joana Stelzer \\ ${ }^{2}$ Everton das Neves Gonçalves
}

\section{RESUMO}

A presente pesquisa contrastou as diretrizes que organizam o comércio internacional e o fenômeno do consumismo. Considerou-se a existência de um ordenamento jurídico mundial que visa à multiplicação de oferta de bens, mas, que não pondera a capacidade de consumo decorrente. Ademais, vislumbra-se a perpetuidade de um modelo jurídico-econômico afastado da sociedade civil e legitimado por procedimento sistêmico tecno-burocrata. Há necessidade premente por um direito global do consumidor. O método de pesquisa utilizado foi o crítico indutivo, os estudos foram bibliográficos. Quanto aos fins, a pesquisa foi exclusivamente descritiva. Os resultados foram expostos em forma de textos.

Palavras-chave: Comércio Internacional; Consumismo; Multilateralismo; Consumidor; Direito Internacional.

\begin{abstract}
The present research contrasted the guidelines that organize international trade and the phenomenon of consumerism. It was considered the existence of a world legal order that aims at the multiplication of the supply of goods, however, that does not weigh the resulting consumption capacity. In addition, the perpetuity of a juridical-economic model that is remote from the civil society and legitimized by techno-bureaucratic systemic procedure is glimpsed. There is a pressing need for a global consumer right. The research method used was the inductive critic, the studies were bibliographical. Regarding the ends, the research was exclusively descriptive. The results were presented in the form of texts.
\end{abstract}

Keywords: International Trade; Consumerism; Multilateralism; Consumer; International Law.

\footnotetext{
${ }^{1}$ Pós Doutoranda na Faculdade de Direito pela Universidade de São Paulo - USP, São Paulo (Brasil). Docente do Programa de Pós-Graduação em Direito pela Universidade Federal de Santa Catarina - PPGD/UFSC, Santa Catarina (Brasil). E-mail: contatojoana@yahoo.com.br

${ }^{2}$ Doctor en Derecho por la Universidad de Buenos Aires - UBA, Buenos Aires (Argentina). Sub-Coordenador do Programa de Pós-Graduação em Direito pela Universidade Federal de Santa Catarina - PPGD/UFSC, Santa Catarina (Brasil). E-mail: evertong@ vetorial.net
} 


\section{Introdução}

O fenômeno do consumismo possui diversos fatores que lhe deram origem e que continuam impulsionando seu movimento. Um ponto que merece destaque, e nem sempre é tão visível aos estudiosos - refere-se à ligação entre as regras do comércio internacional e os padrões de consumo, os estilos de vida, a consciência ambiental, entre outros. Muitas vezes tão festejada a inserção externa dos países, pode ser fator de ameaça à qualidade de vida da sua sociedade.

Em que pese o comércio mundial ter aspectos favoráveis nas relações multilaterais entre os Estados também acarreta perversos resultados, fato que exige ponderar sobre as fórmulas liberalizantes que motivam o sistema de trocas. As construções jurídicas institucionalizadas, com efeito, não têm sido capazes de distribuir riqueza e trazer o prolatado desenvolvimento a vastas camadas da população mundial. Com efeito, o ordenamento jurídico internacional, capitaneado pela Organização Mundial do Comércio (OMC), visa ao desarmamento tarifário e à multiplicação de oferta de bens, mas, sem que haja uma ponderação quanto à capacidade de compra do Estado-membro.

Sob tal contextualização, emerge o seguinte problema investigatório: é possível estabelecer uma relação entre as diretrizes que ordenam o comércio internacional e o fenômeno do consumismo? Documentos internacionais, a exemplo de estudos da Programa das Nações Unidas (PNUD) e de Resoluções dessa instituição, têm lançado alertas acerca do perfil consumista de países que consomem mais que produzem. O comportamento de alguns Estados na seara do comércio internacional e o avanço do multilateralismo reforçam a sociedade de consumo, sem que haja a devida atenção às políticas públicas internas e a um plano de desenvolvimento apropriado.

Sob tal constatação, o objetivo geral da presente investigação consistiu em avaliar a relação existente entre o comércio internacional e o fenômeno do consumismo, apontando o destacado papel que o Direito deve ter para equalizar esse relacionamento. Tendo essa temática como discussão central, os seguintes objetivos específicos foram perseguidos: descrever a evolução do comércio internacional e seus instrumentos jurídicos; discutir o consumismo, enquanto fenômeno que alcança também os Estados; e, destacar normas internacionais que ponderam sobre normas protetivas ao consumidor.

O estudo se justifica, pois o ordenamento comercial internacional deveria sempre ter o ser humano como meta inarredável, contudo, além do lucro ser o mote que impulsiona o 
sistema, nem mesmo questões ligadas ao consumo responsável são suficientemente discutidas. As trocas externas, embasadas pela racionalidade normativa e questões egóicas que comandam o processo, não deveriam conduzir os Estados ao precipício existencial da sociedade de consumo.

Entre as teorias que se apresentaram para avaliar a marcha histórica das trocas internacionais, contribuíram Eros Roberto Grau, Juan Tugores e Rabih Ali Nasser. No âmbito da discussões sobre a sociedade de consumo foram utilizados Zygmunt Bauman e Gilles Lipovetsky. Finalmente, a última parte da pesquisa serviu-se da Resolução 39/248 da Assembléia Geral da ONU e de documentos do Programa das Nações Unidas para o Desenvolvimento (PNUD) para avaliar os efeitos que o consumismo tem provocado em países periféricos.

O método utilizado foi o crítico indutivo, pois foi feita abordagem analítica para a compreensão de uma das dimensões do fenômeno do consumismo. Os dados e as informações foram examinados sob forma qualitativa. Os meios de pesquisa foram exclusivamente bibliográficos, coletados por duas fontes secundárias de informação: prioritariamente, a partir de produção científica de reconhecidas obras doutrinárias; e, também, documentos de importantes Organizações Internacionais. Quanto aos fins, a pesquisa apresentou-se de cunho exclusivamente descritivo, pois pretendeu somente tecer uma relação fenomenológica entre comércio internacional e o consumismo, sem propor um novo referencial. Os resultados foram expostos exclusivamente em forma de textos.

\section{0 comércio internacional: breve perspectiva histórica}

O multilateralismo surgiu num contexto no qual os Estados se preocupavam com o restabelecimento harmônico do sistema econômico mundial, sob a égide do fenômeno da globalização. O Acordo denominado General Agreement on Tariffs and Trade (GATT) foi resultado, em 1947, de um acordo internacional com estrutura institucional mínima, que previa somente a celebração de conferências entre as chamadas partes-contratantes. Inicialmente assinado por vinte e três países, era um Tratado de trinta e oito artigos, incluindo os princípios diretores da liberalização das trocas que objetivava promover. O GATT funcionou como um grande centro de negociações multilaterais do comércio até a emergência da Organização Mundial do Comércio (OMC), em 1995. 
A história do comércio internacional e das relações de força entre os Estados é mais antiga, momento no qual a força bruta (e não o Direito institucionalizado) era regra incontestável. A livre circulação de mercadorias constitui a base do comércio e revelou ser um aspecto fundamental na formação da sociedade. O trânsito de bens encontra raízes na história da economia europeia medieval, que desconhecia o capitalismo industrial, tanto nas técnicas (concentração de trabalhadores assalariados), quanto no espírito (individualismo do empresário para aumentar seu lucro). O desenvolvimento da comercialização de mercadorias, porém, inaugurada particularmente em torno do tecido, fincou muito cedo um capitalismo comercial. Nesse ponto, a produção têxtil originada dos pequenos produtores em suas oficinas artesanais, associada ao domínio dos mercadores (grandes comerciantes) que vendiam esses bens em outras localidades, pode ser considerada como o embrião comercial. (STELZER, 2004).

A época medieval apenas desenvolveu algumas teorias acerca do comércio, enquanto a Igreja se preocupava com a usura e a concorrência (evidentemente, não questionava acerca de si mesma, já que sempre estaria escorada em leis divinas a justificar seu procedimento).

Tal divisão de trabalho em operações especializadas favoreceu a preeminência do empresário financista, que colocava dinheiro na produção têxtil e dirigia o conjunto das operações; mas não foi a divisão do trabalho que engendrou o capitalismo comercial, pois, em numerosas cidades onde os negociantes de panos não ultrapassavam os limites do mercado local ou regional, a indústria têxtil permaneceu confinada numa economia artesanal urbana de fraca envergadura, ignorando o capitalismo comercial que se desenvolveu apenas em alguns centros. No caso, de fato, foram as condições de venda (mercado internacional), antes das técnicas propriamente ditas (divisão do trabalho), que determinaram as formas capitalistas de produção. (ANTONIETTI, 1997, p. 85).

No século XIV ocorreu uma grave crise conjuntural e uma necessidade de readaptação, lançando as bases da modernidade. Na agricultura, o esgotamento do solo diminuiu a produção; a crise demográfica ocorreu com a peste negra; e, a diminuição das trocas trouxe a crise monetária. A depressão, dessa forma, implicou a prática de políticas intervencionistas, seja porque o rei precisava fortalecer-se no poder, porque a burguesia tinha que superar a dificuldade dos negócios (o que traria pesados direitos aduaneiros sobre os produtos estrangeiros), ou porque o povo precisava garantir sua subsistência. Essas raízes do mercantilismo viram na circulação superavitária de mercadorias fator exponencial para o desenvolvimento econômico.(STELZER, 2004, p. 45-46)

Por volta do século XVI, registraram-se mudanças positivas no âmbito da circulação de bens, ocasião na qual os mercadores obtiveram o reconhecimento da comunidade. Os ideais 
dos descobrimentos marítimos foram realizados e a Igreja cedeu quanto às restrições impostas aos negócios. Com o nascimento dos primeiros Estados modernos, desenvolveram-se os sentimentos nacionais, pois apenas uma nação poderosa poderia promover exportações e acumular riquezas, conquistando colônias, ganhando guerras e dominando rotas marítimas.

O comércio de toda a sorte de produtos ganhava acelerada projeção internacional. Nascidos no mesmo contexto, Estado moderno e capitalismo caminhavam lado a lado, cada um viabilizando o outro por meio do mercantilismo.” (FRANCO; CHACON, 2002, p. 111) Nessa fase histórica, o consumo ainda está atrelado à satisfação das necessidades individuais, os Estados negociam seus excedentes e não se vislumbram distorções na relação comércio e consumo.

As reações à política mercantilista logo se fizeram sentir, de modo a recuperar a mais ampla circulação de produtos. Tratava-se do liberalismo econômico. "Dessa teoria se deduz que, do valor produzido pelo trabalhador, o proprietário da terra e o dono do acervo se apropriam de uma parte do rendimento, de onde ter sido Smith o primeiro a apresentar com clareza o conceito de 'mais valia' e a frisar que esta se acha ligada à produção capitalista." (LIMA, 1976, p. 28).

Na Inglaterra, emergiu a Revolução Industrial, merecendo a terminologia 'Revolução' pelas consequências que desencadeou, representando o ponto de apoio para o surgimento do capitalismo industrial e do desejo de fazer circular bens manufaturados. O segundo momento da Revolução (último quarto do século XIX) foi marcado pelas descobertas de novas técnicas (a exemplo do aço, substituindo o ferro; a energia elétrica e o petróleo, ocupando o lugar do vapor), pelo suposto aperfeiçoamento dos conjuntos de métodos trabalhistas e pela racionalização do tempo empregado nas atividades dos funcionários, além de incentivar os setores dos transportes e das comunicações. (STELZER, 2004, p. 52)

Nesse momento, são lançadas as sementes do consumo que supera o ritmo da produção artesanal. A velocidade de compra precisa ser a velocidade da máquina, incentivada por estratégias de um marketing embrionário. Paralelamente, há uma sociedade que consegue se aproximar de produtos com preços mais acessíveis. Os denominados estudos de mercado ganham projeção. Logística e produtividade são temas que começam a ser estudados.

As reações às escolas liberais foram desenvolvidas na segunda metade do século XIX, como consequência de uma série de problemas sociais gerados pela expansão desenfreada do capitalismo industrial. Na verdade, o conjunto de leis naturais, supostamente responsável pela 
auto-regulação do sistema, não mais se sustentava diante das crises que abalavam as economias nacionais. A principal reação ao classicismo veio com a escola socialista, desenvolvida, notadamente, por Karl Marx e Friedrich Engels.

Nesse ponto, deve ser concedida atenção aos estudos desenvolvidos por John Maynard Keynes, o keynesianismo. Após a Crise de 1929, a Inglaterra e o mundo mergulharam em depressão e desemprego, revelando a insustentabilidade das coordenadas gerais da doutrina clássica, absolutamente liberalista, ou seja, na qual as mercadorias deveriam gozar de irrestrito trânsito. "Keynes entregou-se a reflexões sobre os mais graves problemas do sistema capitalista e, descrente do laissez-faire e do automatismo auto-regulador das economias de mercado, procurou encontrar a terapêutica exata que possibilitasse a recuperação dos países abalados pela Grande Depressão.” (ROSSETTI, 1991, p. 117.)

Não por outro motivo, o intervencionismo estatal teria que se fazer presente no modelo capitalista. De Estado liberal transitou-se ao chamado Estado social, concebido como instrumento de justiça social e desenvolvimento. Nessa fase, a disciplina jurídica da atividade econômica começou a ganhar todo seu esplendor, pois ao direito coube ordenar, o que as leis naturais da economia não tinham organizado.

\begin{abstract}
Neste instante, há ainda a pressuposição da livre concorrência das forças de mercado, que o Estado deve assegurar, como o melhor caminho para a realização dos interesses sociais; admite-se já, no entanto, a necessidade de o Estado interferir no jogo das concorrências para restaurar seu 'equilíbrio natural'. A seguir, no entanto, surge o momento social, quando então se admite que não há coerência entre o livre jogo das forças de mercado e o interesse social; o Estado passa a ser o responsável pelo processo econômico e, definindo políticas, a dirigi-lo. A 'mão invisível' de Adam Smith é então substituída pela 'mão visível' do Estado, conformadora de ordem econômica." (GRAU, 1981, p. 18).
\end{abstract}

Com tais referências históricas, alcança-se uma melhor compreensão do fenômeno da globalização, de modo a acompanhar o papel que a ciência jurídica poderia (ou deveria) ter e de como o consumo vai se afirmando enquanto falsa necessidade. Permite-se visualizar em que medida foi possível ao chamado Estado-nação acompanhar a velocidade dos acontecimentos, de modo a mover-se em conjunto com outros Estados no palco internacional.

Somente após a construção de um baluarte jurídico hábil a enfrentar os dilemas da globalização, foi possível fazer as mercadorias trafegarem livremente, muito além das fronteiras políticas nacionais. Nesse sentido, importa perceber os primeiros delineamentos do fenômeno global.

Com isso, de artesanal a industrial, de liberal a intervencionista, da paz à guerra, a 
circulação de mercadorias tem tido papel relevante na história do crescimento dos países (com ou sem desenvolvimento). Na qualidade de causa ou de consequência das mudanças no ritmo da história econômica, a compreensão do movimento consumista, no seio do direito do comércio internacional, faz surgir sua natureza verdadeiramente dialética. A razão de ser da aproximação dos países constitui, igualmente, o objetivo derradeiro de se ter uma sociedade de consumidores. Não por outro motivo, o investigador precisa se debruçar sobre os múltiplos aspectos da sociedade de consumo, obrigando-se a equalizar questões de cunho econômico, político e jurídico, intimamente imbricados na nova dinâmica mundial.

O multilateralismo, quando surge no pós-guerra, em 1947, reafirmou a tentativa de estabelecer um sistema uniforme entre os países, restaurando a ordem econômica internacional. Por um lado, a proposta multilateral aparece em momento caracterizado pela superação histórica do Estado liberal, existente na Revolução Industrial e na Revolução Francesa. Sob outro ângulo, também se deixava para trás um Estado intervencionista, que tomava para si a condução econômica (mas que também se conduzia, sob o signo do individualismo, para os conflitos armados). "O surgimento do sistema multilateral de comércio coincide com a tentativa de se estabelecer um equilíbrio entre essas concepções extremadas (Estado liberal intervencionismo estatal) das funções que deveriam ser desempenhadas pelos Estados no âmbito econômico." (NASSER, 2009, p. 42)

A evolução do sistema multilateral deveria liberalizar o comércio entre os Estadosmembros, a partir da assunção de compromissos no âmbito do direito internacional econômico com vista ao desarmamento tarifário e à resolução de possíveis litígios, de forma institucionalizada. Nesse sentido, posicionou-se também o Comitê Econômico e Social da Comunidade Europeia:

O segredo do êxito [...] de GATT e OMC transparece, sobretudo, em dois domínios:
a definição de normas comerciais, adotadas sempre por consenso de todos os Estados-
membros e tendo, por isso, em conta as suas diferentes necessidades, e um modo de
resolver litígios, caracterizado por uma prudente combinação de pragmatismo e
legalismo adaptada a cada caso. Não há dúvida de que a ameaça de sanções comerciais
subjacentes às decisões do painel se reveste de importância decisiva. (COMITÊ
ECONÔMICO E SOCIAL, 2015, p. 60 .

Com isso, substituir-se-iam as diversas regulamentações nacionais por uma de cunho mundial. Os Estados não deveriam intervir nesse processo de liberalização e, para tanto, seriam convencidos dos benefícios que o sistema trazia. Percebia-se uma institucionalização crescente do sistema, de modo a garantir a observância das regras e, fundamentalmente, o alcance dos 
objetivos liberalizantes.

Em síntese, duas concepções podem ser levadas em consideração acerca do multilateralismo. Primeiro, que a emergência de um organismo internacional regulador do comércio trazia estabilidade ao sistema. De uma forma geral, repudiavam-se os conflitos armados (especialmente de proporção mundial), eis que a ideia de comércio livre clamava por harmonia entre vendedores e compradores. Segundo, que o chamado livre comércio (Free Trade) encerrava muitas desigualdades entre os participantes, tornando relativas as conquistas divulgadas. Sob a ótica de Juan Tugores, "um verdadeiro comércio livre requer apenas algumas linhas para plasmar-se, mas, quando um acordo requer quinhentos e cinqüenta páginas, é sinal que as exceções, cautelas e salvaguardas são extraordinariamente numerosas.” (TUGORES, 2009, p. 84).

No caso do GATT/47, trinta e oito artigos enumerados em quatro capítulos trataram dos mais variados temas. A principiologia do GATT/47 foi mantida pelo GATT/94, assim como as premissas do Tratado Original, acrescidas as inovações da Rodada Uruguai. Portanto, restava como objetivo da OMC, eliminar todas as formas de discriminação do comércio e protecionismo internacional, equalizando tarifas aduaneiras e outras barreiras que viessem a interromper ou dificultar o fluxo internacional de comércio. A velocidade das máquinas na Revolução Industrial era agora também do comércio. Desenhava-se, também, uma sociedade que precisaria consumir para manter o sistema em pleno funcionamento.

De forma geral, o GATT/94 - tanto quanto a OMC - alinhou seus objetivos com uma política de concorrência interna liberal, assim como, com políticas de comércio internacional voltadas para a competitividade entre nações eliminando barreiras e restrições às transações competitivas sempre atentando para o uso eficiente dos recursos econômicos de forma que a máxima smithiana possa ser lembrada no sentido de que os benefícios da competitividade no comércio entre nações devem maximizar as expectativas da melhor forma possível. Não havia nenhuma preocupação de como ocorreria o consumo ou de que maneira seriam feitas as abordagens ao consumidor, sob a estratégia de um marketing global.

À evidência, não se ponderava nessa lógica as nefastas consequências para os países que não conseguiriam participar das regras do jogo. Assim, dentro do modelo neoliberal político-econômico, as regras do GATT/94 no âmbito da OMC restaram articuladas em uma perspectiva de mercado no qual a metodologia individualista e racional buscava a satisfação das necessidades dos agentes de forma egóica, sob forte influência dos valores oriundos dos 
países centrais.

Era a consolidação do complexo fenômeno da globalização econômica. Com os novos ventos que sopravam, reformularam-se as teorias do comércio internacional e a própria atuação do Estado, por intermédio de sua influência político-jurídica. Até esse momento, os nefastos efeitos que estavam por vir ao consumidor, não cabiam em nenhuma mesa de negociação.

\section{0 consumismo e sua conexão com o comércio internacional: em busca de um direito global do consumidor}

Partindo do pressuposto de que os Estados participam em processo interativo no mercado mundial, entende-se pela necessidade de desenvolver um direito global integrado que atente ao fenômeno do consumo (e sua patologia, o consumismo). Em que pese parecerem assuntos distintos, a história do liberalismo, a Revolução Industrial e as regras do comércio internacional servem de base para explicar a compulsão ao consumo. A agilização do processo industrial fez transbordar a oferta, impulsionando o consumidor a adquirir o que precisava e o que não precisava. Trata-se do que Bauman já havia anunciado para o fenômeno do consumo “tem raízes tão antigas quanto os seres vivos [...] é parte permanente e integral de todas as formas de vida [...]". Mas, enquanto o consumo constitui uma característica e ocupação de todos os seres humanos enquanto indivíduos, o consumismo é um "atributo da sociedade" (BAUMAN, 2008, p. 42).

Embora se possa defender de maneira unidimensional um consumo sustentável, isso não ocorrerá enquanto as bases jurídicas e sociais não respaldarem um novo padrão comportamental. Uma sociedade que queira evitar a patologia consumista não pode descuidar dos padrões impostos pelo Direito do Comércio Internacional, pela interatividade que as duas áreas compartilham. Por essa razão, é preciso vislumbrar uma espécie de convergência entre os ideais humanistas de consumo sustentável e os princípios da ordem econômica, sob risco de um ameaçar o outro.

A sociedade capitalista que vigora caracteriza-se por intensa necessidade de consumo, seja por meio dos mercados internos, seja por meio do mercado internacional. O que promoveu a mescla de ambos os mercados foi a globalização. O consumidor sentiu a necessidade de consumir a vasta gama do que é produzido, independente da sua necessidade. Costa informa que conceito de consumo conspícuo foi estabelecido pelo economista norte-americano 
"Thorstein Veblen (1857-1929), em sua obra A Teoria da Classe Ociosa, publicada em 1899, para referir-se ao dispêndio feito com a finalidade precípua de demonstração de condição social. Manifesta-se por meio da compra de artigos de luxos e de gastos ostentatórios" Costa (2000, p. 232).

O Efeito Demonstração envolve a situação em que os indivíduos de um estrato social procuram copiar padrões de comportamento de estratos superiores, tentando demonstrar um status que não possuem. O efeito de demonstração é intensamente utilizado na publicidade, sugerindo que bastaria o simples consumo de determinados produtos para ascender na escala social. Costa (2000, p. 233)

A necessidade de uma perspectiva que possa amenizar as angústias que rondam os ideais de uma ordem jurídica mundial mais equilibrada resta lançada. É o que se propõe, pois não se desconhecem as estremas dificuldades que deverão ser vencidas frente a um histórico desequilíbrio entre o individual e o coletivo, entre o atraso e o desenvolvimento, entre os métodos jurídico-coercitivo e jurídico-persuasivo. De qualquer maneira, o debruçar sobre novas soluções precisa ser exercitado para lançar alternativas capazes de fomentar a discussão e viabilizar estratégias na busca do bem-estar social, econômico e jurídico. (GONÇALVES; STELZER, 2016)

Um direito global que possa levar em consideração tanto as regras do multilateralismo comercial quanto os danos promovidos pelo consumismo é a revelação que necessita ser trazida à tona. $\mathrm{O}$ fenômeno jurídico através de análises empíricas da realidade e do entendimento teórico-social necessita ligar as duas áreas. Embora não se possa reduzir o Direito ao simples fenômeno social, este é também determinante daquele, na medida em que, através da observação empírica e dentro de um curso histórico-evolutivo, podem ser acompanhadas as transformações da Ciência jurídica conforme ser verifique uma relação dialética fato-norma em que um determina e modifica o outro.

O que se percebe é que as normas do Direito Comercial Internacional não correspondem às expectativas sociais, perpetuando um modelo econômico vigente, afastandose da sociedade civil e legitimando-se em um procedimento sistêmico tecno-burocrata. $\mathrm{O}$ resultado derradeiro é a inobservância de questões fundamentais envolvendo a pessoa humana, lançando-a sobre o mercado como imposição do denominado Free Trade. Mas, a liberdade não é do consumidor. Costa (2016) esclarece que o consumo - pela teoria econômica convencional - deveria 'enobrecer' o sujeito, atribuindo-lhe 'soberania. Mas, o que acontece é o contrário, finda por escravizá-lo. “O descarte dos artigos já não é provocado pela mediocridade da 
fabricação, mas pela economia da velocidade, por produtos novos, mais eficientes ou que respondam a outras necessidades" (LIPOVETSKY, 2007, p. 92).

É nesse sentido que se defende o direito do consumidor mais próximo dos direitos humanos. Para Heraldo Felipe de Faria (2016), os acordos de liberação do comércio internacional ativeram-se principal e inicialmente apenas à fixação de tarifas e à ampliação de mercados.

No entanto, tem havido crescente preocupação das relações entre o comércio e os direitos humanos, o que inclui a tutela do consumidor. As organizações de proteção dos direitos humanos e de proteção do consumidor têm pressionado para que os acordos enfoquem outros aspectos relativos aos direitos fundamentais. (FARIA, 2016)

De fato, não há como "se esquivar da análise de uma tentativa de implementação dos Direitos Humanos, tendo como cenário o espectro das transformações das relações sócioeconômicas e seus corolários, sobretudo quando visamos instrumentalizar para isso as práticas jurídicas e os operadores do Direito por elas responsáveis [...]” (MORAIS, 2002, p. 116).

O manancial sociológico pode viabilizar a análise de diversas categorias jurídicas, como o conceito sociológico de Direito, a eficácia das normas jurídicas, o perfil dos operadores jurídicos, a implementação de novas técnicas no processo judicial, entre outros.

As ciências sociais, destarte, permitem introduzir a realidade na formação dos juristas, fazendo-os perceber o quotidiano e as repercussões fáticas do Direito, alcançando uma prática jurídica legitimada pelo social. Em síntese, é necessário delimitar uma interdisciplinaridade rumo a uma nova concepção científica não hermética de interpretação das manifestações jurídicas em meio aos fatos sociais. Um enfoque funcional do Direito do Comércio Internacional, não deve apenas garantir um comércio que logre exclusivamente a circulação cada vez mais intensa de produtos, mas que leve em consideração um consumo sustentável.

Considerando a existência de uma teoria econômica que, simultaneamente, exerce um papel normativo e positivo no estudo dos institutos do Direito, emerge possível uma interpretação capaz de compreender o universo jurídico, partindo de pressupostos econômicos, mas com a possibilidade de alcançar um direito de consumo sustentável. Com isso, o Direito Comercial Internacional deveria engendrar nova ordem econômica global, para enfrentar os desafios do consumo de forma intra-sistêmica e na qual um direito global do consumidor poderia ser incluído, até mesmo para evitar o denominado 'neoconsumidor', indivíduo manipulado, preso a uma estrutura dominante, embora móvel, "o indivíduo-órbita zapeando as coisas na esperança, muitas vezes frustrada, de zapear sua própria vida". (LIPOVETSKY, 2007, 
p. 70).

Não há mais espaço para a unitarização do pensar e proceder ou, ainda, de pensar o econômico e o humano de maneira estanque. Igualmente, não há sentido no isolacionismo seja no âmbito individual ou de coletividades inteiras, na medida em que os agentes econômicos inter-reagem em busca da satisfação de suas necessidades e dentro da perspectiva máxima de otimização de ganhos e de minimização de prejuízos. Verifica-se, em verdade, como condição sine qua non dessa fase do desenvolvimento, a defesa dos interesses econômicos pessoais e coletivos. Não por outro motivo, é preciso encontrar alternativas que levem em consideração aspectos jurídicos, sociológicos e econômicos, sob pena do homem sucumbir em meio à desordem física e espiritual que desarticula sua própria existência e a dos demais.

É preciso realizar o direito do consumidor dentro do sistema econômico mundial, sob risco de sucumbir na utopia ou no idealismo. No caso específico do Direito, deve ser aventada a possibilidade de sugerirem-se modificações na realidade social exposta a partir de uma pragmática interpretação normativo-econômica. Trata-se de perspectiva não isolacionista, pois se percebe que a história do ilimitado consumo caminhou pari passu com a história do comércio internacional.

\section{A Resolução 39/248 da Assembléia Geral da ONU: as consequências humanas do consumismo}

Em 22 de março de 1999 a Comissão sobre o Desenvolvimento Sustentável das Nações Unidas trouxe ao Conselho Econômico e Social da Organização das Nações Unidas (ONU) o projeto de resolução para ampliação e inclusão nas Diretrizes das Nações Unidas para a Proteção do Consumidor. Tratava-se, então, da adoção da Resolução 39/248 da Assembléia Geral, de 9 de abril de 1985, na qual foram aprovadas diretrizes das relações de consumo.

Buscava-se com a normativa auxiliar os países para criação e monitoramento jurídicopolítico de adequada e eficiente proteção ao consumidor. A Resolução 39/248 (UNITED NATIONS, 2016) considera uma série de fatores que levam à preocupação pelos consumidores, a começar por seus interesses e necessidades, particularmente nos países em desenvolvimento. Para isso, reconhece que os consumidores enfrentam muitos desequilíbrios quanto à capacidade econômica e poder de negociação, destacando a importância de promover um desenvolvimento econômico e social justo, equitativo e sustentado, e a proteção do meio ambiente (UNITED 
NATIONS, 2016).

Sob tal perspectiva, a Resolução traz importantes diretrizes para a proteção do consumidor, dentre as quais:

a) Ajudar os países a lograr ou manter uma proteção adequada de seus habitantes na qualidade de consumidores; b) Facilitar as modalidades de produção e distribuição que respondam às necessidades e aos desejos dos consumidores; c) Instar a quem se ocupa da produção de bens e serviços e de sua distribuição aos consumidores a que adotem estritas normas éticas de conduta; d) Ajudar os países a por freio às práticas comerciais abusivas de todas as empresas, em nível nacional e internacional, que prejudiquem os consumidores; e) Facilitar a criação de grupos independentes de defesa do consumidor; f) Fomentar a cooperação internacional na esfera da proteção do consumidor; g) Promover o estabelecimento no mercado de condições que viabilizem aos consumidores uma melhor seleção a preços mais baixos; h) Promover um consumo sustentável.

Naturalmente é de conhecimento que a Resolução não é obrigatória no âmbito do direito internacional, pois sua força imperativa não passa de mera diretriz geral ao desenvolvimento de política protetiva ao consumidor. Por essa mesma razão, não há que se falar em imposição de sanção.

A Resolução traz em sua redação a necessidade do Estado formular normativas comprometidas com verdadeira proteção do consumidor, determinando "manter uma política enérgica de proteção ao consumidor, tendo em conta as diretrizes que figuram mais adiante e os acordos internacionais, pertinentes" (UNITED NATIONS, 2016). Ainda nesse sentido, complementa que cada governo "deve estabelecer suas próprias prioridades [...] segundo as circunstâncias econômicas, sociais e ecológicas do país e as necessidades de sua população e tendo presentes os custos e os benefícios das medidas que se proponham" (UNITED NATIONS, 2016).

Quanto ao comércio internacional, também há diretrizes para serem atendidas e que serão aplicáveis aos bens e serviços produzidos no país como aos importados. Nesse sentido, determina a Resolução: "Ao aplicar quaisquer procedimentos ou regulamentos para a proteção do consumidor, deverá velar-se para que não se converta em barreiras para o comércio internacional e que sejam compatíveis com as obrigações do comércio internacional" (UNITED NATIONS, 2016). Não deixa de ser polêmica a norma quanto a esse quesito, caso se avalie a regra por raciocínio inverso. Vale dizer, não se tem lembrança que na OMC haja regra de liberalização do comércio 'desde que não se ofenda a proteção integral do consumidor'. Necessário se faz um dinâmico Direito interpretado à luz da eficiência e da racionalidade econômica, mas não se desprezando uma visão social dos fenômenos, maxime quando envolve 
os direitos do consumidor.

A seriedade nessa seara é tão significativa que se torna importante lembrar o caso de El Salvador, fato revelador de um Estado rendido ao consumismo perante a ineficiência das normas públicas e de sua danosa relação com o mercado mundial. Nesse país, exige-se mudança no modelo atual de desenvolvimento, em virtude de ter se transformado no terceiro país mais consumista do mundo (relação consumo/PIB) (depois do Lesoto e da Libéria). O Informe sobre Desenvolvimento Humano - 2010 esclarece que o país consome mais que produz: "em 2009, para cada US\$100 que o país produziu, foram consumidos US\$102.4 (calculado entre o gasto das famílias e governo)". (PNUD, 2010)

Mas, como a República de El Salvador, país em torno de 6,2 milhões de habitantes, o menor da América Central e mais densamente povoado chegou a tal situação. Em síntese, de acordo com o Relatório, houve uma abertura comercial agressiva que começou com reduções unilaterais dos direitos aduaneiros de importação e que culminou com a negociação de tratados de livre comércio com os sócios comerciais mais importantes (Estados Unidos, União Europeia, México, Panamá, República Dominicana). Na continuidade, houve uma diminuição dos direitos aduaneiros aplicados ao produtos agrícolas com redução de 20,4\% em 1989 para 1,5\% em 2009; e, adoção de câmbio fixo e consolidação da dolarização para as operações de comércio internacional. Havia, ainda, ausência de coesão social, fragilidade institucional (especialmente por privilegiar o favoritismo na Administração Pública) e baixos níveis de crescimento e investimento (PNUD, 2010). Nesse sentido:

\footnotetext{
Os hábitos de consumo mudaram. Atualmente, dedica-se mais dinheiro a comer fora de casa que à saúde, mais à comunicação que à educação. Uma porcentagem considerável de famílias têm altos níveis de endividamento, em grande medida pelo uso irresponsável do uso de cartão de crédito que bancos e financeiras outorgam com pouco cuidado à capacidade de pagamento e sem instruções claras de uso. [...] com essa tendência de possuir o último de telefone celular ou de pagar prestações para uma televisão maior somente para ver partidas de futebol. Cidadãos que exijam qualidade no que adquirem e que consomem com responsabilidade ao meio ambiente fazem falta.
}

Retrata-se o alerta de Bauman (2008) ao sustentar o 'consumismo', ou seja, que se realiza quando o consumo assume o papel-chave que na sociedade de produtores era exercido pelo trabalho. Dessa maneira, o consumismo passa a ser central quando:

[...] a capacidade profundamente individual de querer, desejar e almejar deve ser, tal como a capacidade de trabalho na sociedade de produtores, destacada ('alienada', o termo aqui empregado não em conotação pejorativa) dos indivíduos e reciclada/reificada numa força externa que coloca a 'sociedade de consumidores' em 
movimento e a mantém em curso como uma forma específica de convívio humano, enquanto ao mesmo tempo estabelece parâmetros específicos para as estratégias individuais de vida que são eficazes e manipula as probabilidades de escolha e conduta individuais". (BAUMAN, 2008, p. 42).

O Relatório (PNUD, 2010), de qualquer modo, também procura identificar alternativas de solução para tão devastadora situação salvadorenha, ao registrar que o diagnóstico, os resultados e as propostas oferecidas dependem em grande medida do conhecimento, da sensibilidade e da visão disponível dentro de uma determinada sociedade. Sob tal contexto, verifica-se a necessidade e a premência de políticas públicas atreladas a um ordenamento matizado pelo comércio internacional, capaz de fornecer as diretrizes seguras para inserção externa sem comprometer a sociedade. Sob outro ângulo, reforça-se também a proteção integral do consumidor (hipossuficiente) e a importância do aspecto educacional da sociedade, de maneira a não se curvar às imposições publicitárias (especialmente das grandes marcas internacionais), de maneira a evitar o consumismo.

\section{Conclusão}

A dinâmica do comércio internacional, viabilizando efetivo e irrestrito trânsito de bens, não traz somente a descrição de inserção dos Estados no sistema mundial de trocas, mas, revela detalhes raramente anunciados relativos ao fenômeno do consumismo. Quando o mundo virou a página de sua história, passadas duas guerras mundiais, o fenômeno da globalização emergiu vigoroso. As mudanças que a Revolução Industrial já tinham acarretado entravam em acelerado ritmo, exigindo que a sociedade - por intermédio do consumo - acompanhasse pari passu o intenso ritmo do comércio externo.

A ordem jurídica mundial, contudo, não se preocupou com o elemento humano dessa relação. Por isso inarredável sempre a afirmação que desenvolvimento não é consequência automática de crescimento econômico e do comércio exterior, exigindo que o Estado tenha a pessoa humana como centro de suas preocupações, com destaque para o consumidor. Almejase um ordenamento progressista e eficaz, que responda às exigências da realidade global, mas que não faça do consumo um instrumento de autodestruição social.

Relatórios Internacionais revelam a deficiência do sistema internacional no que refere à interface entre o estímulo do comércio mundial e um direito global do consumidor. Cumpre defender uma espécie de convergência entre os ideais protetivos consumeristas e os princípios 
da ordem econômica, sob risco de um ameaçar o outro. As propostas do multilateralismo precisam de uma orientação não calcada exclusivamente sobre a estrutura burocrática, pautada sobre o direito aduaneiro ou sobre o desarmamento tarifário. O Relatório denominado 'Informe sobre Desarrollo Humano El Salvador 2010', do Programa das Nações Unidas para o Desenvolvimento (PNUD), evidencia que os países não conseguem se desenvolver integralmente se perpetuarem um desempenho medíocre. Mas, é preciso romper com o modelo vigente.

Sob tal perspectiva, iniciativas pautadas pelo agrobusiness, substituição de importações, promoção de exportações ou atração de investimentos possuem uma deficiência elementar, pois embora se preocupem com a inserção internacional do país, não possuem um contraponto na inserção do consumidor nesse sistema. No intuito de guiar solução intermédia revela-se necessária a defesa de um Direito Global de Consumo, possibilitador de desenvolvimento econômico sem desconhecer os limites do consumo.

\section{Referências}

ANTONIETTI, Guy. A economia medieval. Tradução de Hilário Franco Júnior. São Paulo: Atlas, 1997.

BAUMAN, Zygmunt. Vida para o Consumo: a transformação das pessoas em mercadorias. Rio de Janeiro: Zahar, 2008.

COMITÊ ECONÔMICO E SOCIAL. Parecer sobre a Organização Mundial do Comércio. Bruxelas: Documentação interna, 27.01.1999. CES 66/99 DE-EP. Disponível em: http://www.eesc.europa.eu/?i=portal.pt.home Acesso em: 28/05/2015.

COSTA, Fernando Nogueira da. Economia em 10 Lições. São Paulo: MakronBooks, 2000.

FARIA, Heraldo Felipe. Proteção do Consumidor como Direito Fundamental em Tempos de Globalização. Disponível em:

http://revistaeletronicardfd.unibrasil.com.br/index.php/rdfd/article/viewFile/41/41 A Acesso em: 04/09/2016.

FRANCO Jr., Hilário; CHACON, Paulo Pan. História econômica geral. São Paulo: Atlas, 2002 .

GONÇALVES, Everton das Neves; STELZER, Joana. Críticas e Possibilidades da Análise Econômica do Direito. Disponível em: http://coloquioepistemologia.com.br/ Acesso em: 04/09/2016. 
GRAU, Eros Roberto. Elementos de direito econômico. São Paulo: Revista dos Tribunais, 1981.

LIMA, Heitor Ferreira. História do pensamento econômico no Brasil. São Paulo: Companhia Editora Nacional, 1976.

LIPOVETSKY, Gilles. A felicidade paradoxal: ensaio sobre uma sociedade de hiperconsumo. São Paulo: Companhia das Letras, 2007.

MORAIS, José Luiz Bolzan de. Direitos Humanos "Globais e (Universais)" de todos, em todos os lugares. In: PIOVESAN, Flávia. (Org.) Direitos Humanos, Globalização Econômica e Integração Regional. São Paulo: Max Limonad, 2002.

NASSER, Rabih Ali. A liberalização do comércio internacional nas normas do GATT - OMC. São Paulo: LTr, 2009.

PNUD. (Programa de las Naciones Unidas para el Desarrollo). Informe sobre Desarrollo Humano EI Salvador 2010. De la pobreza y el consumismo al bienestar de la gente. Propuestas para un nuevo modelo de desarrollo. Disponível em: http://hdr.undp.org/sites/default/files/reports/246/indh_el_salvador_2010.pdf Acesso em: 04/09/2016.

ROSSETI, José Paschoal. Introdução à economia. 17.ed. São Paulo: Atlas, 1991.

STELZER, Joana. Mercado Europeu: direito e análise jurisprudencial. Curitiba: Juruá, 2004.

TUGORES, J. Economía internacional: globalización e integración regional. 4.ed. Madrid: Mc Graw Hill, 2009.

UCA (Universidad Centroamericana José Simeón Cañas). Por un consumo responsable y sostenible (editorial). Disponível em: http://www.uca.edu.sv/noticias/texto-2421 Acesso em: 04/09/2016.

UNITED NATIONS. A/RES/39/248. Disponível em:

http://www.un.org/documents/ga/res/39/a39r248.htm Acesso em: 04/09/2016. 